\title{
Health related quality of life in patients with idiopathic pulmonary fibrosis in clinical practice: insights-IPF registry
}

Michael Kreuter ${ }^{1,24^{*}}$, Jeff Swigris², David Pittrow ${ }^{3}$, Silke Geier ${ }^{4}$, Jens Klotsche ${ }^{5}$, Antje Prasse ${ }^{6,7,24}$, Hubert Wirtz ${ }^{8}$, Dirk Koschel ${ }^{9}$, Stefan Andreas ${ }^{10}$, Martin Claussen ${ }^{11,24}$, Christian Grohé $^{12}$, Henrike Wilkens ${ }^{13}$, Lars Hagmeyer ${ }^{14}$, Dirk Skowasch ${ }^{15}$, Joachim F Meyer ${ }^{16}$, Joachim Kirschner ${ }^{17}$, Sven Gläser ${ }^{18,19}$, Felix J. F. Herth ${ }^{1,24}$, Tobias Welte ${ }^{6,24}$, Claus Neurohr ${ }^{20,24}$, Martin Schwaiblmair ${ }^{21}$, Matthias Held ${ }^{22}$, Thomas Bahmer ${ }^{11,24}$, Marion Frankenberger 20,23,24 and Jürgen Behr ${ }^{20,23,24}$

\begin{abstract}
Background: The INSIGHTS-IPF registry provides one of the largest data sets of clinical data and self-reported patient related outcomes including health related quality of life (QoL) on patients with idiopathic pulmonary fibrosis (IPF). We aimed to describe associations of various QoL instruments between each other and with patient characteristics at baseline.

Methods: Six hundred twenty-three IPF patients with available QoL data (St George's Respiratory Questionnaire SGRQ, UCSD Shortness-of-Breath Questionnaire SoB, EuroQol visual analogue scale and index EQ-5D, Well-being Index WHO-5) were analysed. Mean age was $69.6 \pm 8.7$ years, $77 \%$ were males, mean disease duration $2.0 \pm 3.3$ years, FVC pred was $67.5 \pm 17.8 \%$, $\mathrm{DL}_{\text {co }}$ pred $35.6 \pm 17 \%$.

Results: Mean points were SGRQ total 48.3, UCSD SoB 47.8, EQ-5D VAS 66.8, and WHO-5 13.9. These instruments had a high or very high correlation (exception WHO-5 to EQ-5D VAS with moderate correlation). On bivariate analysis, QoL by SGRQ total was statistically significantly associated with clinical symptoms (NYHA; $p<0.001$ ), number of comorbidities $(p<0.05)$, hospitalisation rate $(p<0.01)$ and disease severity (as measured by GAP score, CPI, FVC and 6-min walk test; $p<0.05$ each). Multivariate analyses showed a significant association between QoL (by SGRQ total) and IPF duration, FVC, age, NYHA class and indication for long-term oxygen treatment.
\end{abstract}

Conclusions: Overall, IPF patients under real-life conditions have lower QoL compared to those in clinical studies. There is a meaningful relationship between QoL and various patient characteristics.

Trial registration: The INSIGHTS-IPF registry is registered at Clinicaltrials.gov (NCT01695408).

Keywords: Patient related outcomes, Psychometrics, Idiopathic pulmonary fibrosis, Cohort study

\section{Background}

Idiopathic pulmonary fibrosis (IPF) is a chronic, fibrosing interstitial lung disease associated with a high symptom burden, significant comorbidities and early death [1-3]. Median survival is $3-5$-years, shorter than for many malignancies [4]. The antifibrotic drugs, pirfenidone

\footnotetext{
* Correspondence: kreuter@uni-heidelberg.de

${ }^{1}$ Center for interstitial and rare lung diseases, pneumology and respiratory critical care medicine, Thoraxklinik, University of Heidelberg, Röntgenstr. 1, D-69126 Heidelberg, Germany

${ }^{24}$ German center for Lung Research, Aulweg 130, 35392 Gießen, Germany Full list of author information is available at the end of the article
}

and nintedanib, slow lung function decline but have not been convincingly shown to improve survival or quality of life (QoL) [5, 6]. Beside prolonging survival, major aims for IPF therapy include improving symptoms and QoL domains like physical functioning, social participation and emotional well-being [7].

A number of patient-reported outcome (PRO) measures have been used in IPF research [8]. However, the majority of PRO data were generated in single-center cohorts or controlled clinical trials, and there are very limited QoL response data from IPF patients collected under 
real-world conditions. Such data could be used to improve understanding of disease burden at the individual and group levels, to better discern response to therapeutic interventions and to plan for trials of novel therapies.

In the present study, we aimed to summarize QoL data collected in a nationwide, "real-world", observational registry of patients with IPF and to examine associations between QoL and several other clinical variables.

\section{Methods}

INSIGHTS-IPF ("Investigating significant health trends in idiopathic pulmonary fibrosis") is an investigator-initiated, multicenter (19 centers from all parts of Germany), observational registry study of data collected, within the confines of routine clinical care, from patients with IPF since November 2012. The study materials were approved by the Ethics Committee of the Medical Faculty, Technical University of Dresden, and by further local ethic committees as per local requirements. INSIGHTS-IPF is registered at Clinicaltrials.gov (NCT01695408). The protocol $[9,10]$ and a detailed description of the baseline characteristics of the cohort [1] have been previously published. In brief, patients are eligible for enrolment if they are at least 18 years old, have IPF (definite, probable or possible, applying the 2011 IPF guideline [11]) based on physician diagnosis, and have provided written informed consent. There are no explicit exclusion criteria. Clinical data are collected at enrolment and thereafter at 6-month intervals. At follow-up visits, events such as hospitalization and acute exacerbation (as judged by the treating physician) are recorded. Data are reported via a secure internet based data collection form.

\section{Patient-reported outcome measures}

Enrollees complete PROs at enrolment and yearly thereafter. PROs include the University of California San Diego Shortness of Breath Questionnaire (UCSD SOB), the St. George's Respiratory Questionnaire (SGRQ), World Health Organization-5 Well-Being Index (WHO-5) and the EuroQol five-dimensional questionnaire (EQ-5D).

\section{UCSD SOB}

This questionnaire includes 24 items, each with a response scale 0 (Not at all) to 5 (Maximally or Unable to do because of breathlessness). The total score ranges from 0 to 120 , with a higher score indicating more severe dyspnea $[12,13]$.

\section{SGRQ}

The SGRQ was originally developed for patients with chronic obstructive pulmonary disease or asthma [14], however, as a respiratory disease-specific instrument, it has frequently been used in IPF [15]. There are 50 items divided into three components (symptoms, activity, and impacts). Scores for each component and a total score range from 0 (highest QoL) to 100 (poorest QoL).

\section{WHO-5}

The 5 items of the questionnaire tap mood, vitality, and general health. Each item is scored 0 to 5 . The total ranges from 0 to 25 , with higher scores connoting better well-being.

\section{$E Q-5 D$}

The EQ-5D taps 5 domains (mobility, self-care, usual activities, pain or discomfort, and anxiety or depression) and is commonly used in cost-utility evaluation. Based on domain scores, a sum utility score is calculated ranging from negative values ( -0.59 worse than death) to 1 (perfect state). Respondents also rate their current health on a $20-\mathrm{cm}$ vertical visual analogue scale (VAS) scored from 0 to 100 [16].

\section{Data collection and statistical analysis}

Data were collected using an internet-based case report form (eCRF) with automated plausibility checks. On-site monitoring, with source data verification, was performed in the majority of centers (currently 70\%).

Summary statistics were generated for baseline data. Pearson product-moment correlation coefficients and univariate linear regression were used to examine associations between variables. Backward selection was used to generate multivariable models using the following candidate variable: disease duration, long-term oxygen therapy, physician's judgment on IPF behavior (stable, slowly or rapidly progressing), NYHA stage, duration since first symptoms in years, GAP index [17], number and type of comorbidities (left heart insufficiency, coronary heart disease (CHD), carotid stenosis, stroke, peripheral arterial disease, atrial fibrillation, deep venous thrombosis (DVT), pulmonary arterial embolism, pulmonary hypertension, arterial hypertension, reflux, diabetes mellitus, emphysema, lung cancer, obstructive sleep apnea, depression/ depressive disorder, anxiety), 6-min walk distance, gender, hospitalization in last 12 months, pulmonary rehabilitation, and CPI. Standard errors and confidence intervals were estimated by the Huber White sandwich estimator to account for the clustering of patients within the study centers. Data were analyzed with STATA 12.1 (StataCorp LP. Stata Statistical Software: Release 12. College Station, TX, USA).

\section{Results}

Baseline characteristics

Data for QoL were available for 623 of a total of 737 patients (84.5\%). Baseline characteristics are presented in Table 1. Patients mean age was $69.6 \pm 8.7$ years, $77.2 \%$ 
Table 1 Baseline characteristics

\begin{tabular}{|c|c|}
\hline Characteristic & Value \\
\hline Male sex & $481(77.2 \%)$ \\
\hline Age, years & $69.6 \pm 8.7$ \\
\hline Body mass index, $\mathrm{kg} / \mathrm{m}^{2}$ & $27.5 \pm 4.1$ \\
\hline Underweight & $4(0.6 \%)$ \\
\hline Normal weight & $167(26.8 \%)$ \\
\hline Overweight & $305(49.0 \%)$ \\
\hline Obesity & $147(23.6 \%)$ \\
\hline Age at first symptom onset, years & $65.8 \pm 10.1$ \\
\hline Age at IPF diagnosis, years & $67.6 \pm 9.6$ \\
\hline Duration since first symptoms, years & $3.6 \pm 4.0$ \\
\hline Disease duration, years & $2.0 \pm 3.3$ \\
\hline Disease duration of less than 6 months & $242(38.8 \%)$ \\
\hline \multicolumn{2}{|l|}{ Smoking status } \\
\hline Never & $237(38.0 \%)$ \\
\hline Former & $376(60.4 \%)$ \\
\hline Current & $10(1.6 \%)$ \\
\hline Gastro-oesophageal reflux & $192(30.8 \%)$ \\
\hline Emphysema & $55(8.8 \%)$ \\
\hline Genetic predisposition & $31(5.0 \%)$ \\
\hline Six-minute walk distance, meters & $272.4 \pm 196.1$ \\
\hline$\%$ FVC & $67.5( \pm 17.8)$ \\
\hline$\% \mathrm{FEV}_{1}$ & $75.3( \pm 19.4)$ \\
\hline$\% \mathrm{DL}_{\mathrm{CO}}$ & $35.6( \pm 17.0)$ \\
\hline Long term oxygen use & $201(32.3 \%)$ \\
\hline \multicolumn{2}{|l|}{ GAP index } \\
\hline Stage I & $87(20.2 \%)$ \\
\hline Stage ॥ & $238(55.2 \%)$ \\
\hline Stage III & $106(24.6 \%)$ \\
\hline
\end{tabular}

Based on sample of patients with HrQoL data $(n=623)$. Values are $\mathrm{n}(\%)$ or mean \pm standard deviation

GAP Gender, Age, Physiology index

were male; all but one were Caucasian (99.7\%). Their mean FVC was $67.5 \pm 17.8 \%$ predicted and DLCO $35.6 \pm 17 \%$ predicted. A comparison of baseline characteristics of the 623 patients with and 114 patients without available QoL data can be found in Additional file 1: Table S1.

Patients were treated with antifibrotic therapies (49.5\%), oral glucocorticoids (23.7\%); N-acetylcysteine (33.7\%), and long-term $\mathrm{O} 2$ therapy (32.3\%). Most (90.0\%) had definite IPF, $5 \%$ probable IPF, and 5\% possible IPF. At enrolment, treating physicians rated IPF as stable in $36.3 \%$, slowly progressing in $30.9 \%$ and rapidly progressing in $11.2 \%$.

\section{PRO scores and their inter-correlations at enrolment}

Baseline values for PROs and their inter-correlations are shown in Table 2. According to the SGRQ, the greatest impairment was in the activity component. Based on the WHO-5 index, $46.4 \%$ of the patients showed depressive symptoms.

\section{Associations between PRO scores and clinical variables at enrolment}

For the SGRQ, associations with various demographic and clinical characteristics of patients at baseline are shown in Fig. 1. Statistically significantly higher total SGRQ score (indicating reduced QoL) were associated with lower age ( 51.8 for patients $\leq 60$ years versus 46.9 for patients $>65$ years), female gender ( 46.9 for male versus 53 for female), higher NYHA classes (compared to NYHA class I), longer duration of symptoms, higher CPI, lower \%FVC, and higher GAP stage (Fig. 1). Correlations between QoL and \%DLCO (EQ-5D: 0.28, $p<0.001$; SGRQ: $-0.26, p<0.001$; UCSD: $-0.22, p<0.001)$ or \%FVC (EQ-5D: $0.33, p<0.001$; SGRQ: $-0.40, p<0.001$; UCSD: $-0.43, p<0.001)$ were moderately strong. Patients without comorbidity had a mean SGRQ total score of 44; those with 2 comorbidities 47; and those with $\geq 4$ comorbidities 59 (ANOVA, $p<0.001$ for difference between groups) (Table 3 ). QoL was also significantly associated with some types of pharmacological and non-pharmacological therapies of patients with IPF (Table 4).

In multivariate models (Table 5), LTOT, GAP index (stage III), physician's judgement (rapid progression), and NYHA class were independent predictors of EQ-5D VAS. The same variables (except for the GAP index) were associated with SGRQ total score.

Both the EQ-5D index and the EQ-5D TTO were statistically significantly associated with LOT, the 6-MWD and the NYHA functional class (II, III, and IV). The WHO-5 was associated with LOT, and NYHA class III and IV. Finally, the UCSD SoB was associated with LOT, and NYHA class and \%FVC.

\section{Discussion}

Idiopathic pulmonary fibrosis (IPF) is not only a severe life-shortening disease; it also significantly impairs patients' quality of life. In this study, we present data from a large cohort of IPF patients. To our knowledge, this is one of the first-presentations of such data collected under real-world conditions. Overall, impairment in QoL and symptom burden were immense.

Compared to a very recent report from the Australian IPF registry, QoL impairment was very similar with a SGRQ total score of 46.6 (and 48.3 in our registry). Similarly, to the data presented here, an association between QoL and dyspnoea and physiological data were reported. Yet, in contrast to our analyses also cough and depression were major contributors to diminished QoL reasons for this may be explained by different tools used to assess depression (HADS) and a structured 
Table 2 Correlations between different measures of QoL at baseline

\begin{tabular}{|c|c|c|c|c|c|c|c|c|c|}
\hline & mean (SD) & $\begin{array}{c}\text { EQ-5D } \\
\text { VAS }\end{array}$ & $\begin{array}{l}\text { EQ-5D } \\
\text { Index }\end{array}$ & WHO-5 & $\begin{array}{l}\text { SGRQ } \\
\text { total }\end{array}$ & $\begin{array}{c}\text { SGRQ } \\
\text { symptoms }\end{array}$ & $\begin{array}{l}\text { SGRQ } \\
\text { activity }\end{array}$ & $\begin{array}{c}\text { SGRQ } \\
\text { impacts }\end{array}$ & $\begin{array}{c}\text { UCSD } \\
\text { Shortness } \\
\text { of breath }\end{array}$ \\
\hline EQ5D VAS & $60.0(19.7)$ & 1 & 0.62 & 0.56 & -0.67 & -0.51 & -0.62 & -0.63 & -0.69 \\
\hline EQ5D Index & $66.8(21.3)$ & & 1 & 0.66 & -0.70 & -0.45 & -0.65 & -0.69 & -0.73 \\
\hline WHO-5 & $13.9(6.0)$ & & & 1 & -0.67 & -0.47 & -0.57 & -0.67 & -0.67 \\
\hline SGRQ & $48.3(20.7)$ & & & & 1 & 0.77 & 0.91 & 0.96 & 0.88 \\
\hline SGRQ symptoms & $57.2(21.2)$ & & & & & 1 & 0.60 & 0.68 & 0.64 \\
\hline SGRQ activity & $62.3(24.2)$ & & & & & & 1 & 0.79 & 0.85 \\
\hline SGRQ impacts & $37.9(21.8)$ & & & & & & & 1 & 0.83 \\
\hline UCSD Shortness of breath & $47.8(31.2)$ & & & & & & & & 1 \\
\hline
\end{tabular}

Green fields highlight very strong $(r \geq 0.80)$ or strong $(r \geq 0.60-0.79)$ correlations, yellow fields moderate $(r=0.30-0.59)$ correlation

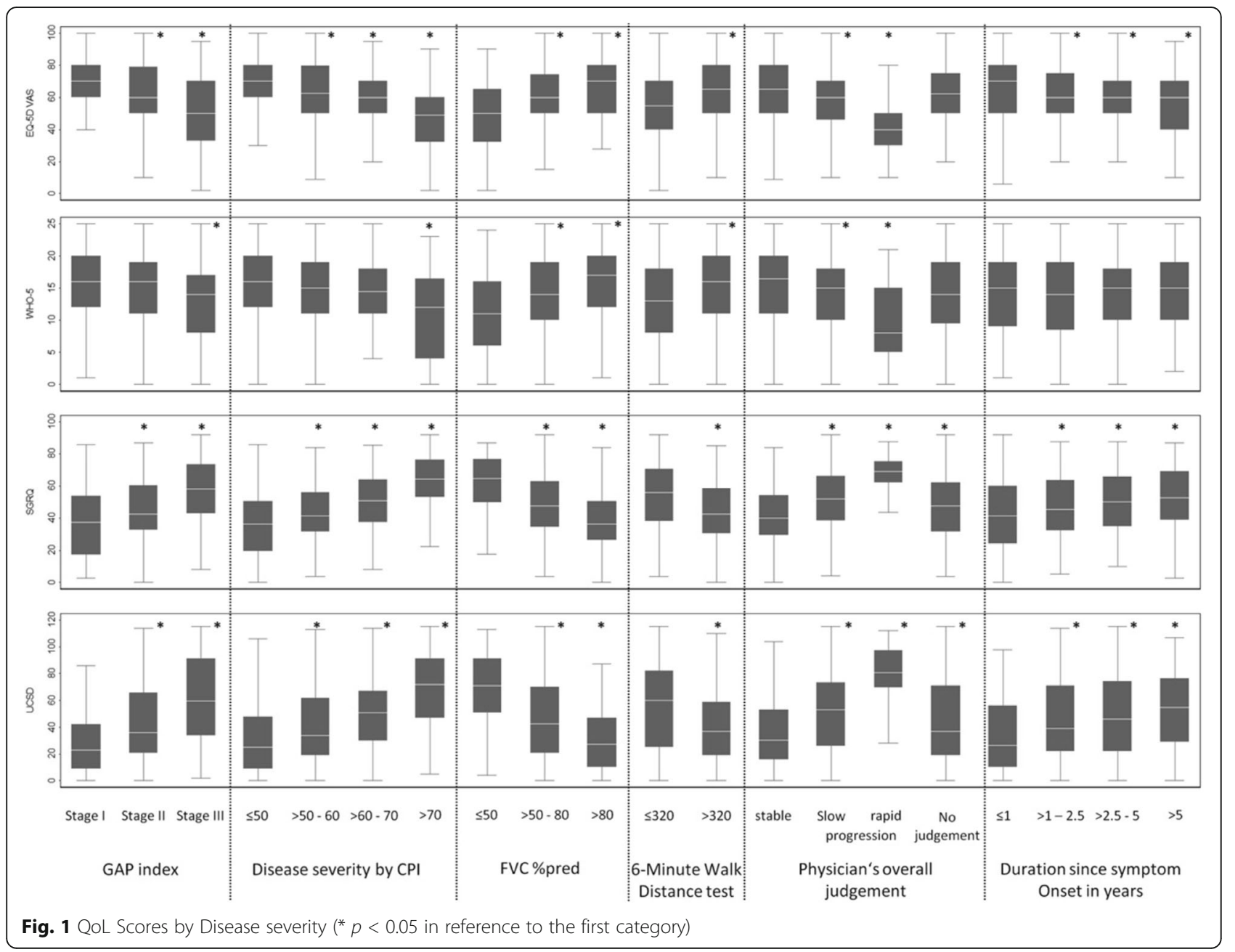




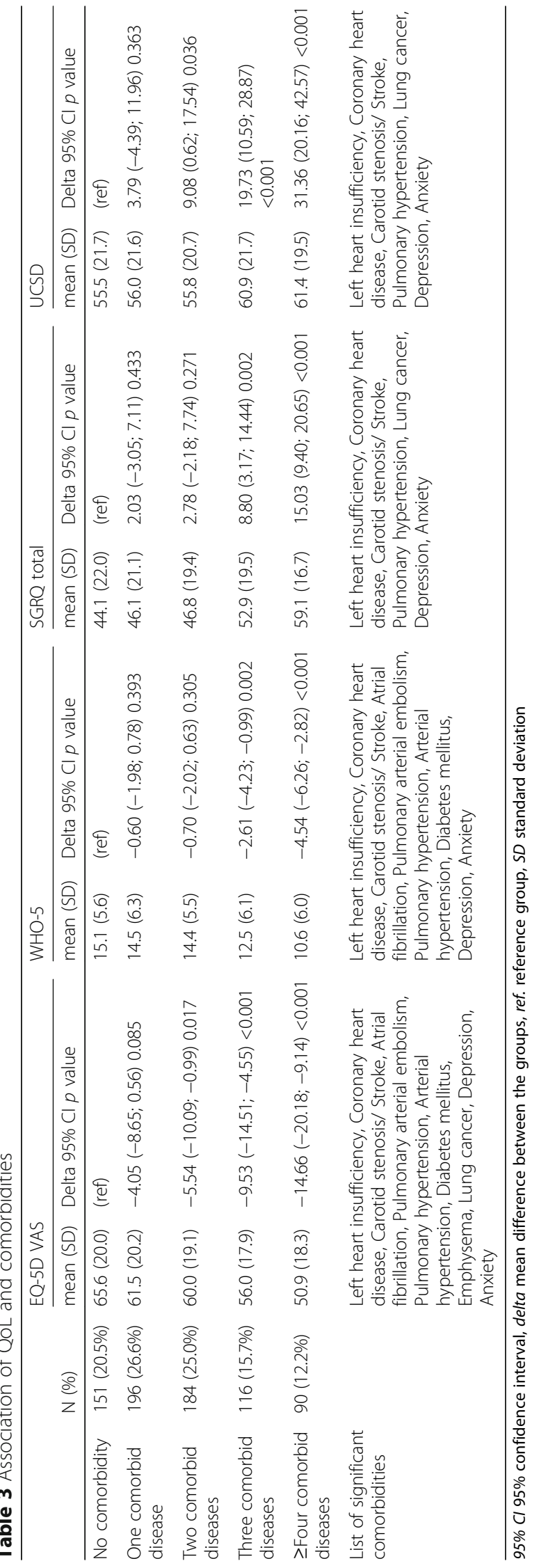




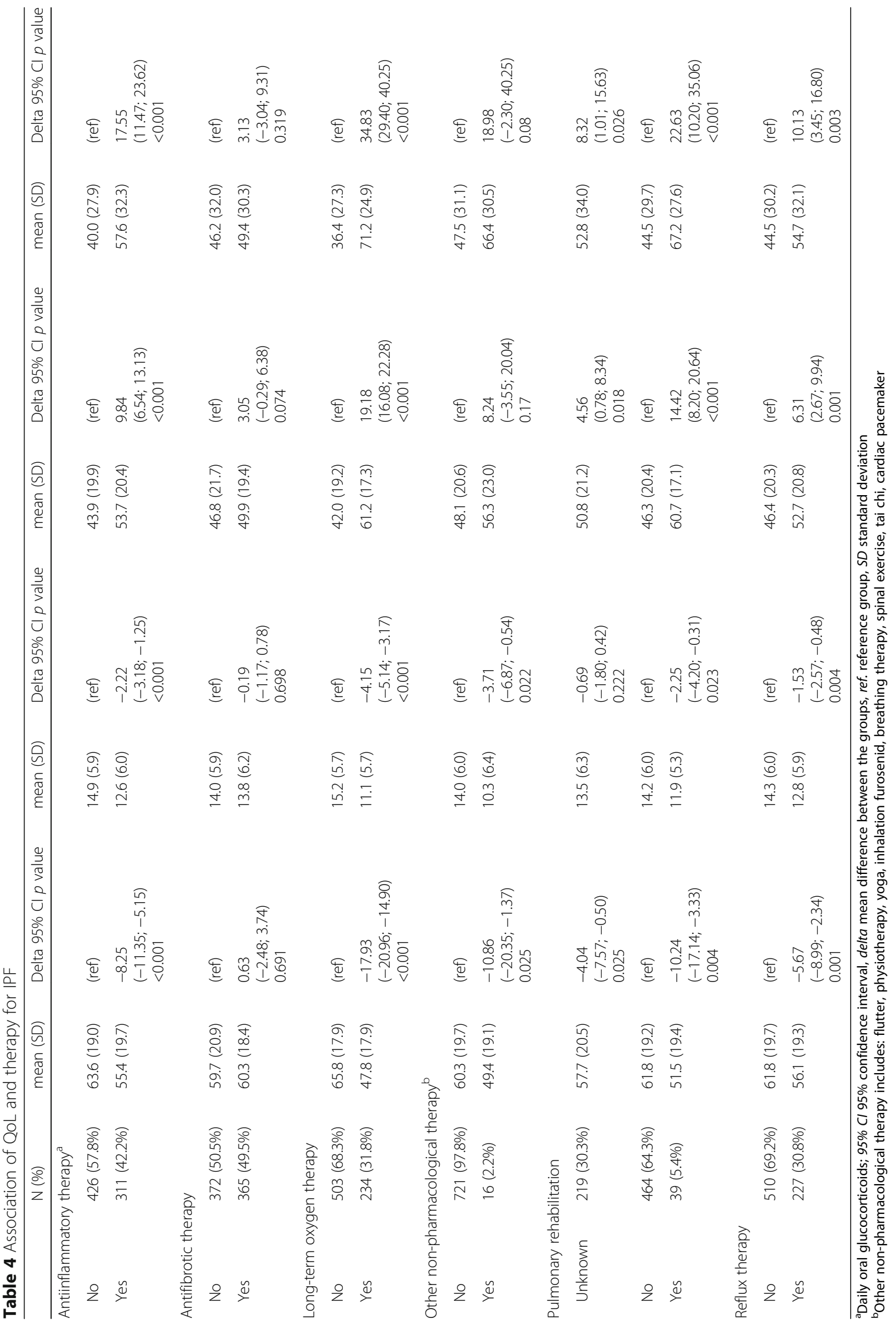


Table 5 Predictors of QoL in stepwise multivariable linear regression analyses

\begin{tabular}{|c|c|c|c|c|}
\hline & EQ-5D VAS & WHO-5 & SGRQ & UCSD \\
\hline & Beta $95 \% \mathrm{Cl} p$ value & Beta $95 \% \mathrm{Cl} p$ value & Beta $95 \% \mathrm{Cl} p$ value & Beta $95 \% \mathrm{Cl} p$ value \\
\hline Age & & & $0.280 .05 ; 0.520 .018$ & \\
\hline Disease duration in months & & & $0.070 .02 ; 0.120 .010$ & \\
\hline \multicolumn{5}{|l|}{ GAP index } \\
\hline Stage I & (ref) & & & \\
\hline Stage \| & $-5.02-10.78 ; 0.740 .087$ & & & \\
\hline Stage III & $-12.24-19.71 ;-4.780 .001$ & & & \\
\hline \multicolumn{5}{|l|}{ Physician's overall judgment } \\
\hline Stable disease & (ref) & (ref) & (ref) & \\
\hline Slow progression & $-5.46-12.48 ; 1.550 .126$ & $-0.42-1.61 ; 0.760 .484$ & $2.59-3.36 ; 8.540 .392$ & \\
\hline Rapid progression & $-15.28-25.42 ;-5.140 .003$ & $-2.74-4.73 ;-0.750 .007$ & $9.061 .35 ; 16.760 .021$ & \\
\hline No judgement possible & $-5.43-12.72 ; 1.860 .144$ & $-0.43-1.68 ; 0.810 .495$ & $2.40-3.98 ; 8.770 .460$ & \\
\hline Long-term oxygen therapy & $-14.31-20.66 ;-7.95<0.001$ & $-3.20-4.32 ;-2.08<0.001$ & $7.421 .74 ; 13.100 .011$ & $22.9913 .50 ; 32.48<0.001$ \\
\hline \multicolumn{5}{|l|}{ NYHA functional class } \\
\hline I & (ref) & & (ref) & (ref) \\
\hline$\|$ & $-8.52-15.67 ;-1.370 .020$ & & $12.855 .76 ; 19.94<0.001$ & $15.787 .55 ; 24.01<0.001$ \\
\hline III & $-7.40-15.36 ; 0.550 .068$ & & $21.0513 .06 ; 29.04<0.001$ & 28.96 18.96; $38.95<0.001$ \\
\hline IV & $-24.87-37.41 ;-12.32<0.001$ & & $29.6319 .32 ; 39.94<0.001$ & $38.4922 .48 ; 54.51<0.001$ \\
\hline FVC \%pred & & $0.040 .01 ; 0.070 .006$ & $-0.21-0.36 ;-0.060 .005$ & $-0.33-0.57 ;-0.09<0.001$ \\
\hline
\end{tabular}

Considered variables in stepwise multivariable linear regression analyses: Disease duration, FVC \%pred, Long-term oxygen therapy, Age, Physician's overall judgment, NYHA stage, Duration since first symptoms, GAP index, No. of comorbidities, 6MWD, Sex, Hospitalisation in last 12 months, Pulmonary rehabilitation, CPI

tool to assess cough severity [18]. Another, yet retrospective very recently published cohort of 182 IPF patients reported an association between the SGRQ total score and overall survival [19]. In comparison to recently-completed, randomised controlled drug trials, the patients in our registry had more severe QoL impairment and a higher symptom burden. For example, in the two INPULSIS trials of nintedanib, which together included 1066 patients, the mean total SGRQ score was 39.4-39.8 points in the various arms [20]; it was 48.3 in our registry. The same is true of other drug trials for IPF: ambrisentan (492 subjects: mean SGRQ total 40.5-44.5) [21], interferon gamma-1b (826 subjects: 41.6-42.4) [22]. Similarly, mean UCSD dyspnea score was higher in this registry (47.8) than participants in recently conducted trials (e.g., the ASCEND trial on pirfenidone, 555 patients, mean UCSD 34.0-36.6 points). [23] Such differences in symptoms and QoL are likely explained by differences in disease severity and baseline characteristics. For example, in our real world cohort, the burden of comorbidities known to portend a worse prognosis in IPF [3] was not insignificant, with $322(51.7 \%)$ of our registry enrollees having at least two comorbid conditions [1]. These patients would have been excluded from most drug trials.

To our knowledge, this is the first time, investigators have assessed the association between the presence of specific comorbid conditions and QoL. We observed that comorbid conditions contribute greatly to QoL impairment. However, additional research is needed to determine if therapeutic targeting comorbidities will improve QoL in these patients. Although other investigators have assessed QoL in IPF patients under real-world conditions, they found no correlation between various baseline characteristics and QoL [24]. This may stem from a lack of power. In our cohort, SGRQ total score was higher in women than men, an observation noted by other investigators [25]. The reason for this difference is unknown but merits further investigation.

Like other investigators, we found that QoL was more impaired in patients on LTOT than in those not on LTOT. In fact, LTOT was an independent predictor of QoL even with adjustment for disease severity $[24,26]$. This likely stems from the real and perceived constraints LTOT places on patients [27]. QoL impairment was also greater among patients who were prescribed anti-inflammatory therapy, anti-reflux therapy and other non-pharmacological interventions. In this observational study, causation cannot be discerned, and more research is needed to improve understanding of these results.

In several studies, investigators reported correlation coefficients between the SGRQ and one or more other patientrelated assessment of health related quality of life, health status or symptoms including the Borg Dyspnea Index 
[26, 28], Cough Quality of Life Questionnaire [29], the Baseline Dyspnea Index [28, 30, 31], King's Brief Interstitial Lung Disease questionnaire, [32, 33] Dyspnea Score [34], Short-Form 36 Physical Component Summary [28], Dyspnea-12 [35], and UCSD SoB questionnaire [7] among others. Overall, there were moderate to strong correlation between the SGRQ total score and the total score of these instruments [15], thus supporting the validity of the SGRQ total to capture QoL in patients with IPF. It is reassuring that data from our study mirror results from these other studies. Like them, our results support the validity of the SGRQ (and the other instruments used in INSIGHTS) for use in IPF, including a large, real-world, German cohort. In future research, shorter questionnaires with longitudinal and cross-cultural validity should be developed for use in daily patient care [32,33].

In IPF patients, a major challenge is how to improve QoL impairment. Currently, only sildenafil, pulmonary rehabilitation or specialized, multi-modality treatment programs may have a role [36-38]. Unfortunately, the two globally-approved anti-fibrotic drugs, nintedanib and pirfenidone, have not been shown to do so. Hopefully, ongoing development and research efforts will lead to therapeutic interventions that allow IPF patients to live better with the disease.

There are limitations to our study. The QoL assessment tools we used were not originally developed for IPF, but they do have data to support their validity in this disease. Instruments such as the K-BILD [32] or A Tool to Assess Quality of Life in Idiopathic Pulmonary Fibrosis (ATAQ-IPF-cA) [39] which were developed for patients with interstitial lung disease may have reflected impairments more precisely in our cohort. However, these instruments' psychometric properties have yet to be examined in German patients. Because all registry patients were being treated in specialized ILD centers, these results may not generalize to the larger IPF population. IPF was diagnosed at the participating centers according to current guidelines without undergoing another central MDT review which may explain some differences between the results reported here and clinical trial cohorts, although recent data suggest that experienced physicians are very accurate in diagnosing IPF [40]. Further, QoL data may have been biased in the cohort reported here as incident IPF patients were slightly underrepresented compared to patients without available HrQoL data. However, a strength of the INSIGHTS-IPF registry is that enrollees were prospectively and consecutively recruited, and it employs source data verification, statistical plausibility checks and queries.

\section{Conclusions}

Health related quality of life is substantially impaired in patients with IPF, and drivers of this impairment include symptoms, comorbidities, LOT and disease severity.
While current treatments improve the course of the disease and perhaps survival, additional investigation is needed to identify interventions that durably to improve this important outcome in IPF patients.

\section{Additional file}

Additional file 1: Table S1. Comparison of baseline characteristics of patients with and without available QoL data (total enrolled patients $n=737)$. (DOCX $15 \mathrm{~kb})$

\section{Acknowledgements \\ Not applicable. \\ Study steering committee members: \\ Michael Kreuter, David Pittrow, Jens Klotsche, Antje Prasse, Hubert Wirtz and Jürgen Behr. \\ Member of the German Center for Lung Research (DZL): \\ Michael Kreuter, Antje Prasse, Martin Claussen, Felix J. F. Herth, Tobias Welte, \\ Claus Neurohr, Thomas Bahmer, Marion Frankenberger and Jürgen Behr.}

\section{Funding}

The registry is supported by Boehringer Ingelheim, Germany. The company has no influence on the conduct of the study or interpretation of data.

Availability of data and materials

All data generated or analysed for this manuscript are included in this published article.

\section{Authors' contributions}

MK, JS, SG, JK, DP and JB analysed and interpreted the data. MK, DP, AP, JK, HuWi and JB are study steering committee members. All authors were involved in collecting the data, in writing the manuscript, and approved the final manuscript.

\section{Ethics approval and consent to participate}

The study materials were approved by the Ethics Committee of the Medical Faculty, Technical University of Dresden (EK 255082012), and by further local ethic committees as per local requirements.

\section{Consent for publication}

Not applicable.

\section{Competing interests}

MK reports grants and personal fees from Roche/InterMune, grants and personal fees from Boehringer Ingelheim, outside the submitted work; AP reports grants and personal fees from Roche/InterMune, grants and personal fees from Boehringer Ingelheim, outside the submitted work; HuWi reports personal fees from Boeringer Ingelheim, personal fees from Roche, outside the submitted work; MC reports personal fees from Boehringer Ingelheim Pharma GmbH, outside the submitted work; DP reports personal fees outside the submitted work from Actelion, Bayer, Boehringer Ingelheim, GSK, Novartis, and MSD.SV reports personal fees from Boehringer Ingelheim, personal fees from Roche Pharma, personal fees from Actelion Pharma, grants and personal fees from Novartis Pharma, personal fees from Berlin Chemie, personal fees from Astra, outside the submitted work; HeWi reports personal fees from Boehringer, personal fees from Roche, during the conduct of the study; personal fees from Bayer, personal fees from Biotest, personal fees from Actelion, personal fees from GSK, personal fees from Pfizer, outside the submitted work; CN Claus Neurohr reports honoraria for lectures and serving on advisory boards from Boehringer Ingelheim and Roche Pharma. SA reports case payments from Boehringer Ingelheim, during the conduct of the study; personal fees from Boehringer Ingelheim, personal fees from Roche, outside the submitted work. TW reports grants from Boehringer, during the conduct of the study; TB reports grants from German Center for Lung Research (DZL), personal fees from Roche, outside the submitted work; JB received grants from Boehringer Ingelheim, InterMune, and Actelion and personal fees for consultation or lectures from Actelion, Bayer, Boehringer-Ingelheim, InterMune and Roche. He is member of the international IPF quideline committee. All other authors declared that they have no competing interests. 


\section{Publisher's Note}

Springer Nature remains neutral with regard to jurisdictional claims in published maps and institutional affiliations

\section{Author details}

${ }^{1}$ Center for interstitial and rare lung diseases, pneumology and respiratory critical care medicine, Thoraxklinik, University of Heidelberg, Röntgenstr. 1 , D-69126 Heidelberg, Germany. ${ }^{2}$ Interstitial Lung Disease Program, National Jewish Health, Denver, CO, USA. ${ }^{3}$ Institut für Klinische Pharmakologie, Medizinische Fakultät, Technische Universität Dresden, Dresden, Germany. ${ }^{4}$ Department Market Access, Boehringer Ingelheim, Ingelheim am Rhein, Germany. ${ }^{5}$ Epidemiologie, Deutsches Rheuma-Forschungsinstitut, Berlin, Germany. ${ }^{6}$ Klinik für Pneumologie, Medizinische Hochschule Hannover, Hannover, Germany. ${ }^{7}$ Fraunhofer Institute ITEM, Hannover, Germany. ${ }^{8}$ Abteilung für Pneumologie, Department Innere Medizin, Neurologie und Dermatologie, Universitätsklinikum Leipzig AöR, Leipzig, Germany. ${ }^{9}$ Zentrum für Pneumologie, Fachkrankenhaus Coswig, Coswig, Germany. ${ }^{10}$ Lungenfachklinik Immenhausen and Universitätsmedizin Göttingen, Kardiologie und Pneumologie, Göttingen, Germany. ${ }^{11}$ LungenClinic Grosshansdorf, Grosshansdorf, Germany. ${ }^{12}$ Klinik für Pneumologie - ELK, Berlin Buch, Berlin, Germany. ${ }^{13}$ Klinik für Innere Medizin V, Pneumologie, Universitätsklinikum Universitätskliniken des Saarlandes, Homburg, Germany. ${ }^{14}$ Krankenhaus Bethanien, Solingen, Germany. ${ }^{15}$ Medizinische Klinik und Poliklinik II, Universitätsklinikum Bonn, Bonn, Germany. ${ }^{16}$ Lungenzentrum München, LZM Bogenhausen-Harlaching, Städtisches Klinikum München $\mathrm{GmbH}$, München, Germany. ${ }^{17}$ Center for Internal Medical Studies CIMS, Bamberg, Germany. ${ }^{18}$ Universitätsmedizin Greifswald, Klinik und Poliklinik für Innere Medizin B, Forschungsbereich Pneumologie und Pneumologische Epidemiologie, Greifswald, Germany. ${ }^{19}$ Vivantes Klinikum Spandau, Klinik für Innere Medizin, Berlin, Germany. ${ }^{20}$ Comprehensive Pneumology Center, Lungenforschungsambulanz, Klinikum der Universität München, München, Germany. ${ }^{21}$ I. Medizinische Klinik, Klinikum Augsburg, Augsburg, Germany. ${ }^{22}$ Klinikum Würzburg Mitte, Standort Missioklinik, Abteilung Innere Medizin, Pneumologie, Würzburg, Germany. ${ }^{23}$ Asklepios Fachkliniken München-Gauting, München, Germany. ${ }^{24}$ German center for Lung Research, Aulweg 130, 35392 Gießen, Germany.

Received: 4 March 2017 Accepted: 3 July 2017

Published online: 14 July 2017

\section{References}

1. Behr J, Kreuter M, Hoeper MM, Wirtz H, Klotsche J, Koschel D, Andreas S, Claussen M, Grohe C, Wilkens H, Randerath W, Skowasch D, Meyer FJ, Kirschner J, Glaser S, Herth FJ, Welte T, Huber RM, Neurohr C, Schwaiblmair M, Kohlhaufl M, Hoffken G, Held M, Koch A, Bahmer T, Pittrow D. Management of patients with idiopathic pulmonary fibrosis in clinical practice: the INSIGHTS-IPF registry. Eur Respir J. 2015;46(1):186-96.

2. Raghu G, Rochwerg B, Zhang Y, Garcia CA, Azuma A, Behr J, Brozek JL, Collard HR, Cunningham W, Homma S, Johkoh T, Martinez FJ, Myers J, Protzko SL, Richeldi L, Rind D, Selman M, Theodore A, Wells AU, Hoogsteden H, Schunemann HJ. An official ATS/ERS/JRS/ALAT clinical practice guideline: treatment of idiopathic pulmonary fibrosis. An update of the 2011 clinical practice guideline. Am J Respir Crit Care Med. 2015;192(2):e3-19.

3. Kreuter M, Ehlers-Tenenbaum S, Palmowski K, Bruhwyler J, Oltmanns U, Muley T, Heussel CP, Warth A, Kolb M, Herth FJ. Impact of comorbidities on mortality in patients with idiopathic pulmonary fibrosis. PLoS One. 2016;11(3):e0151425.

4. Olson AL, Swigris JJ, Lezotte DC, Norris JM, Wilson CG, Brown KK. Mortality from pulmonary fibrosis increased in the United States from 1992 to 2003. Am J Respir Crit Care Med. 2007;176(3):277-84.

5. Rochwerg B, Neupane B, Zhang Y, Garcia CC, Raghu G, Richeldi L, Brozek J, Beyene J, Schunemann H. Treatment of idiopathic pulmonary fibrosis: a network meta-analysis. BMC Med. 2016;14:18.

6. Canestaro WJ, Forrester SH, Raghu G, Ho L, Devine BE. Drug treatment of idiopathic pulmonary fibrosis: systematic review and network meta-analysis. Chest. 2016;149(3):756-66.

7. Swigris JJ, Han M, Vij R, Noth I, Eisenstein EL, Anstrom KJ, Brown KK, Fairclough D. The UCSD shortness of breath questionnaire has longitudinal construct validity in idiopathic pulmonary fibrosis. Respir Med. 2012;106(10):1447-55
8. Yount SE, Beaumont JL, Chen SY, Kaiser K, Wortman K, Van Brunt DL, Swigris J, Cella D. Health-related quality of life in patients with idiopathic pulmonary fibrosis. Lung. 2016;194(2):227-34.

9. Behr J, Hoeper MM, Kreuter M, Klotsche J, Wirtz H, Pittrow D. Characteristics and management of idiopathic pulmonary fibrosis: INSIGHTS-IPF registry. Dtsch Med Wochenschr. 2012;137(49):2586-8.

10. Behr J, Hoeper M, Kreuter M, Klotsche J, Wirtz H, Pittrow D. Investigating significant health trends in idiopathic pulmonary fibrosis (INSIGHTS-IPF): rationale, aims and design of a nationwide prospective registry. BMJ Open Respir Res. 2014;1:e000010. doi:10.1136/bmjresp-2013-000010.

11. Raghu G, Collard HR, Egan JJ, Martinez FJ, Behr J, Brown KK, Colby TV, Cordier JF, Flaherty KR, Lasky JA, Lynch DA, Ryu JH, Swigris JJ, Wells AU, Ancochea J, Bouros D, Carvalho C, Costabel U, Ebina M, Hansell DM, Johkoh T, Kim DS, King TE Jr, Kondoh Y, Myers J, Muller NL, Nicholson AG, Richeldi L, Selman M, Dudden RF, Griss BS, Protzko SL, Schunemann HJ. An official ATS/ERS/JRS/ALAT statement: idiopathic pulmonary fibrosis: evidence-based guidelines for diagnosis and management. Am J Respir Crit Care Med. 2011;183(6):788-824.

12. Ries AL. Minimally clinically important difference for the UCSD shortness of breath questionnaire, borg scale, and visual analog scale. Copd. 2005;2(1):105-10.

13. Kupferberg DH, Kaplan RM, Slymen DJ, Ries AL. Minimal clinically important difference for the UCSD shortness of breath questionnaire. J Cardpulm Rehabil. 2005;25(6):370-7.

14. Jones PW, Quirk FH, Baveystock CM. The St George's respiratory questionnaire. Respir Med. 1991;85(Suppl B):25-31. discussion 33-27

15. Swigris JJ, Esser D, Conoscenti CS, Brown KK. The psychometric properties of the St George's respiratory questionnaire (SGRQ) in patients with idiopathic pulmonary fibrosis: a literature review. Health Qual Life Outcomes. 2014;12:124.

16. Pickard AS, Neary MP, Cella D. Estimation of minimally important differences in EQ-5D utility and VAS scores in cancer. Health Qual Life Outcomes. 2007:5:70.

17. Ley B, Ryerson CJ, Vittinghoff E, Ryu JH, Tomassetti S, Lee JS, Poletti V, Buccioli M, Elicker BM, Jones KD, King TE Jr, Collard HR. A multidimensional index and staging system for idiopathic pulmonary fibrosis. Ann Intern Med. 2012;156(10):684-91.

18. Glaspole IN, Chapman SA, Cooper WA, Ellis SJ, Goh NS, Hopkins PM, Macansh S, Mahar A, Moodley YP, Paul E, Reynolds PN, Walters EH, Zappala CJ, Corte TJ. Health-related quality of life in idiopathic pulmonary fibrosis: data from the Australian IPF registry. Respirology. 2017:22(5):950-6.

19. Furukawa T, Taniguchi H, Ando M, Kondoh Y, Kataoka K, Nishiyama O, Johkoh T, Fukuoka J, Sakamoto K, Hasegawa Y. The St. George's respiratory questionnaire as a prognostic factor in IPF. Respir Res. 2017;18(1):18.

20. Richeldi L, du Bois RM, Raghu G, Azuma A, Brown KK, Costabel U, Cottin V, Flaherty KR, Hansell DM, Inoue Y, Kim DS, Kolb M, Nicholson AG, Noble PW, Selman M, Taniguchi H, Brun M, Le Maulf F, Girard M, Stowasser S, Schlenker-Herceg R, Disse B, Collard HR, Investigators IT. Efficacy and safety of nintedanib in idiopathic pulmonary fibrosis. N Engl J Med. 2014;370(22):2071-82.

21. Raghu G, Behr J, Brown KK, Egan JJ, Kawut SM, Flaherty KR, Martinez FJ, Nathan SD, Wells AU, Collard HR, Costabel U, Richeldi L, de Andrade J, Khalil N, Morrison LD, Lederer DJ, Shao L, Li X, Pedersen PS, Montgomery AB, Chien JW O'Riordan TG. Treatment of idiopathic pulmonary fibrosis with ambrisentan: a parallel, randomized trial. Ann Intern Med. 2013;158(9):641-9.

22. King TE Jr, Albera C, Bradford WZ, Costabel U, Hormel P, Lancaster L, Noble PW, Sahn SA, Szwarcberg J, Thomeer M, Valeyre D, du Bois RM. Effect of interferon gamma-1b on survival in patients with idiopathic pulmonary fibrosis (INSPIRE): a multicentre, randomised, placebo-controlled trial. Lancet. 2009;374(9685):222-8.

23. King TE Jr, Bradford WZ, Castro-Bernardini S, Fagan EA, Glaspole I, Glassberg MK, Gorina E, Hopkins PM, Kardatzke D, Lancaster L, Lederer DJ, Nathan SD, Pereira CA, Sahn SA, Sussman R, Swigris JJ, Noble PW, Group AS. A phase 3 trial of pirfenidone in patients with idiopathic pulmonary fibrosis. N Engl J Med. 2014;370(22):2083-92.

24. Verma G, Marras T, Chowdhury N, Singer L. Health-related quality of life and 6 min walk distance in patients with idiopathic pulmonary fibrosis. Can Respir J. 2011;18(5):283-7.

25. Han MK, Swigris J, Liu L, Bartholmai B, Murray S, Giardino N, Thompson B, Frederick M, Li D, Schwarz M, Limper A, Flaherty K, Martinez FJ. Gender influences health-related quality of life in IPF. Respir Med. 2010;104(5):724-30.

26. Chang JA, Curtis JR, Patrick DL, Raghu G. Assessment of health-related quality of life in patients with interstitial lung disease. Chest. 1999;116(5):1175-82.

27. Belkin A, Albright K, Swigris JJ. A qualitative study of informal caregivers' perspectives on the effects of idiopathic pulmonary fibrosis. BMJ Open Respir Res. 2014;1(1):e000007. 
28. Yorke J, Jones PW, Swigris JJ. Development and validity testing of an IPF-specific version of the St George's respiratory questionnaire. Thorax. 2010;65(10):921-6.

29. Lechtzin N, Hilliard ME, Horton MR. Validation of the cough quality-of-life questionnaire in patients with idiopathic pulmonary fibrosis. Chest. 2013;143(6):1745-9.

30. Nishiyama O, Taniguchi H, Kondoh Y, Kimura T, Ogawa T, Watanabe F, Nishimura K. Health-related quality of life in patients with idiopathic pulmonary fibrosis. What is the main contributing factor? Respir Med. 2005;99(4):408-14.

31. Zimmermann CS, Carvalho CR, Silveira KR, Yamaguti WP, Moderno EV, Salge JM, Kairalla RA, Carvalho CR. Comparison of two questionnaires which measure the health-related quality of life of idiopathic pulmonary fibrosis patients. Braz J Med Biol Res. 2007:40(2):179-87.

32. Patel AS, Siegert RJ, Brignall K, Gordon P, Steer S, Desai SR, Maher TM, Renzoni EA, Wells AU, Higginson IJ, Birring SS. The development and validation of the King's Brief Interstitial Lung Disease (K-BILD) health status questionnaire. Thorax. 2012;67(9):804-10.

33. Kreuter M, Birring SS, Wijsenbeek M, Wapenaar M, Oltmanns U, Costabel U, Bonella F. German validation of the "King's Brief Interstitial Lung Disease (K-Bild) health status questionnaire". Pneumologie. 2016;70:742.

34. Peng S, Li Z, Kang J, Hou X. Cross-sectional and longitudinal construct validity of the Saint George's respiratory questionnaire in patients with IPF. Respirology. 2008;13(6):871-9.

35. Yorke J, Swigris J, Russell AM, Moosavi SH, Ng Man Kwong G, Longshaw M, Jones PW. Dyspnea-12 is a valid and reliable measure of breathlessness in patients with interstitial lung disease. Chest. 2011;139(1):159-64.

36. Olson AL, Brown KK, Swigris JJ. Understanding and optimizing health-related quality of life and physical functional capacity in idiopathic pulmonary fibrosis. Patient Relat Outcome Meas. 2016;7:29-35.

37. Bajwah S, Ross JR, Peacock JL, Higginson IJ, Wells AU, Patel AS, Koffman J, Riley J. Interventions to improve symptoms and quality of life of patients with fibrotic interstitial lung disease: a systematic review of the literature. Thorax. 2013;68(9):867-79.

38. Zisman DA, Schwarz M, Anstrom K, Collard HR, Flaherty KR, Hunninghake GW. A controlled trial of sildenafil in advanced idiopathic pulmonary fibrosis. $\mathrm{N}$ Engl J Med. 2010;363(7):620-8.

39. Yorke J, Spencer LG, Duck A, Ratcliffe S, Kwong GN, Longshaw MS, Belkin A, Swigris JJ. Cross-Atlantic modification and validation of the a tool to assess quality of life in idiopathic pulmonary fibrosis (ATAQ-IPF-CA). BMJ Open Respir Res. 2014;1(1):e000024.

40. Walsh, S; Maher, T; Kolb, M; Poletti, V; Nusser, R; Richeldi, L; Vancheri, C; Wilsher, Ma; Antoniou, K; Behr, J; Bendstrup, E; Brown, K; Calandriello, L; Corte, T; Cottin, V; Crestani, B; Flaherty, K; Glaspole, I; Grutters, J; Inoue, Y; Kokosi, M; Kondoh, Y; Kouranos, V; Kreuter, M; Johannson, K; Judge, E; Ley, B; Margaritopoulos, GA.; Martinez, F; Molina-Molina, M; Morais, A; Nunes, H; Raghu, G; Ryerson, C; Selman, M; Spagnolo, P; Taniguchi, H; Tomassetti, S; Valeyre, D; Wijsenbeek, M; Wuyts, W; Hansell, D; Wells, A. Diagnostic accuracy of a clinical diagnosis of idiopathic pulmonary fibrosis: an international case-cohort study. Eur Resp J 2017. in press.

\section{Submit your next manuscript to BioMed Central and we will help you at every step:}

- We accept pre-submission inquiries

- Our selector tool helps you to find the most relevant journal

- We provide round the clock customer support

- Convenient online submission

- Thorough peer review

- Inclusion in PubMed and all major indexing services

- Maximum visibility for your research

Submit your manuscript at www.biomedcentral.com/submit
C Biomed Central 